\title{
PRODUÇÃO DE DOCUMENTÁRIO SOCIOAMBIENTAL: Contribuições na Formação Discente do Curso Técnico em Controle Ambiental
}

\author{
Barbara Aparecida Nunes Silva ${ }^{1}$ \\ Marcelo Borges Rocha
}

\begin{abstract}
RESUMO
Esta pesquisa tem por objetivo investigar a contribuição do processo de produção de documentário socioambiental na formação de estudantes do Curso Técnico em Controle Ambiental. A Educação Profissional e Tecnológica Integrada tem o trabalho como princípio educativo e o currículo integrado como concepção de ensino-aprendizagem fundamentado na formação humana integral. No currículo integrado, a contextualização do ensino proporciona a integração dos saberes. Nesse sentido, o desenvolvimento colaborativo de mídia educacional, envolvendo uma temática socioambiental, pode contribuir para proporcionar a construção do saber de forma lúdica e criativa. Dessa forma, a pesquisa articulou a produção colaborativa de documentário com a Educação Profissional e Tecnológica Integrada. A pesquisa é do tipo participante e se apoia em Le Boterf (1984) para a configuração do quadro metodológico. Desenvolveu-se oficinas no processo de produção do documentário com um grupo de alunos voluntários do Curso Técnico em Controle Ambiental, e analisou-se os resultados conforme fundamentação teórica, quando se observa a superação da visão fragmentada de meio ambiente e a compreensão holística da temática socioambiental identificada. Palavras-chave: Educação profissional e tecnológica. Documentário socioambiental. Mídia educacional.
\end{abstract}

\section{PRODUCTION OF SOCIO-ENVIRONMENTAL DOCUMENTARY: CONTRIBUTIONS TO STUDENT TRAINING IN THE TECHNICAL COURSE IN ENVIRONMENTAL CONTROL}

\begin{abstract}
This research aims to investigate the contribution of the socio-environmental documentary production process to the training of students in the Technical Course in Environmental Control. Integrated Professional and Technological Education has work as an educational principle and the integrated curriculum as a teaching-learning concept based on integral human formation. In the integrated curriculum, the contextualization of teaching provides the integration of knowledge. In this sense, the collaborative development of educational media involving a socio-environmental theme can contribute to providing the construction of knowledge in a playful and creative way. In this way, the research articulated the collaborative production of documentary with the Integrated Professional and Technological Education. The research is of the participant type and is based on Le Boterf (1984) for the configuration of the methodological framework. Workshops were developed in the documentary production process with a group of volunteer students from the Technical Course in Environmental Control and the results were analyzed according to the theoretical foundation, where it is possible to overcome the fragmented view of the environment and holistic understanding of the identified socio-environmental theme.
\end{abstract}

Keywords: Professional and Technological Education. Socioenvironmental documentary. Educational media.

Recebido em: $28 / 1 / 2020$

Aceito em: $24 / 3 / 2020$

\footnotetext{
Mestrado em Educação Profissional e Tecnológica (Instituto Federal de Educação, Ciência e Tecnologia do Rio de Janeiro - IFRJ, 2020). Especialização em Gestão Escolar e Coordenação Pedagógica (Universidade Gama Filho - UGF, 2010). Graduação em Pedagogia (Universidade do Estado do Rio de Janeiro - Uerj, 2005). Técnica em Assuntos Educacionais no Instituto Federal de Educação, Ciência e Tecnologia do Rio de Janeiro (IFRJ). Docente nos anos iniciais do Ensino Fundamental - Prefeitura de Duque de Caxias. Tem interesse em pesquisas com os seguintes temas: projetos interdisciplinares envolvendo questões sociocientíficas no espaço escolar; enfoque CTS - Ciência, Tecnologia e Sociedade no ensino de ciências; e inserção curricular das tecnologias educacionais, por meio de práticas educativas facilitadoras e inovadoras para potencialização do processo de ensino-aprendizagem. http://lattes.cnpq.br/2212944989846600. https://orcid.org/00000001-5344-0630. barbara.silva@ifrj.edu.br

2 Graduação em Ciências Biológicas (Universidade Federal do Rio de Janeiro, 2000). Mestrado em Educação em Ciências e Saúde - Núcleo de Tecnologia Educacional para a Saúde (2003) e Doutorado em Ciências Biológicas - Zoologia (2011), pela Universidade Federal do Rio de Janeiro. Possui vasta experiência como taxonomista de Polychaeta. Tem experiência na área de Educação, Biologia Marinha e Zoologia, atuando, principalmente, nos seguintes temas: divulgação científica, taxonomia, biologia marinha e biologia molecular. Professor do Ensino Superior e do Programa de Pós-Graduação em Ciência, Tecnologia e Educação do Centro Federal de Educação Tecnológica Celso Suckow da Fonseca (Cefet/RJ). Chefe da Divisão de Editoração, responsável pela Revista Tecnologia e Cultura. http://lattes.cnpq. br/5640018108479090.https://orcid.org/0000-0003-4472-7423 rochamarcelo36@yahoo.com.br
} 
A Educação Profissional Integrada tem como concepções a omnilateralidade do sujeito e o currículo integrado. O cerne do ensino integrado encontra-se nos fundamentos teórico-práticos do currículo integrado, que possibilitam ao sujeito compreender a realidade em sua globalidade com compreensão dos elementos constituintes de um fenômeno social e suas conexões, integrando saberes. O educando desenvolve-se, se humaniza, cria, recria e age sobre a realidade existente com saberes práticos, teóricos e políticos (CIAVATTA, 2005).

Nesse sentido, a produção coletiva de mídia educacional, na área socioambiental, permite a sensibilização e a reflexão crítica de forma lúdica e criativa. As Diretrizes Curriculares Nacionais da Educação Básica - DCNs - (BRASIL, 2013) orientam a abordagem de atividades integradoras para enriquecimento curricular. Assim, a produção coletiva de documentário socioambiental configura-se como uma atividade integradora coerente com a transversalidade na formação de estudantes de cursos técnicos.

Nessa pesquisa, a produção coletiva deu-se com estudantes do curso Técnico em Controle Ambiental Integrado, do Instituto Federal do Rio de Janeiro-IFRJ, Campus Nilópolis. O perfil do egresso, em processo de reconfiguração e análise no campus, considera como um dos seus princípios fundamentais capacitar o concluinte a administrar os entraves da vida social e as questões ambientais, reconhecendo as diferentes visões sobre um determinado fenômeno, traçando estratégias de atuação e integrando os conhecimentos das várias ciências do campo do saber, com inserção no mundo do trabaIho de modo compromissado com o desenvolvimento sustentável. O curso é organizado em oito períodos semestrais, com duração de quatro anos, e se encontra em fase de reestruturação curricular.

Conforme o perfil do egresso, entende-se a importância da contextualização no processo de ensino-aprendizagem para a compreensão global dos fenômenos estudados, em interlocução com diferentes áreas do conhecimento.

Sendo assim, a questão norteadora da pesquisa foi: "Quais as contribuições do processo de produção de documentário socioambiental para a formação de estudantes do curso Técnico em Controle Ambiental?" A hipótese levantada foi que o processo de produção colaborativa possibilita a discussão de questões socioambientais de forma contextualizada e lúdica, contribuindo, assim, para a formação de estudantes do curso Técnico em Controle Ambiental.

Como forma de responder à questão que norteou este estudo, estabeleceu-se como objetivo geral investigar a contribuição do processo de produção de documentário socioambiental na formação de estudantes do curso Técnico em Controle Ambiental. Tal objetivo desdobrou-se nos seguintes objetivos específicos: investigar a visão dos sujeitos da pesquisa em relação às problemáticas ambientais no âmbito do IFRJ, Campus Nilópolis; produzir coletivamente um documentário ambiental conforme temática definida previamente junto aos discentes; e elaborar material virtual para divulgação e replicabilidade do Produto Educacional.

Vale destacar que a pesquisa se tornou importante porque a inserção participativa dos discentes na produção de documentários socioambientais permitiu a reflexão crítica relacionada às questões socioambientais de forma lúdica. 


\section{REFERENCIAL TEÓRICO}

\section{Interconexão de Saberes na Educação Profissional e Tecnológica}

A Educação Profissional e Tecnológica, na perspectiva de educação emancipadora, contempla o indivíduo em suas múltiplas vertentes, indo ao encontro, assim, da educação omnilateral. A omnilateralidade integra a formação humana do educando em sua totalidade, superando as separações entre trabalho, ciência e cultura. O trabalho como princípio educativo constitui o sentido ontológico do ser social (LUKÁCS, 1969). Frigotto (2001, p. 74) assevera que:

(...) o princípio educativo de trabalho - deriva desta sua especificidade de ser uma atividade necessária desde sempre a todos os seres humanos. O trabalho constitui-se, por ser elemento criador da vida humana, num dever e num direito. Um dever a ser aprendido, socializado desde a infância. Trata-se de apreender que o ser humano enquanto ser da natureza necessita elaborar a natureza, transformá-la, pelo trabalho, em bens úteis para satisfazer as suas necessidades vitais, biológicas, sociais, culturais, etc. Mas é também um direito, pois é por ele que pode recriar, reproduzir permanentemente sua existência humana (...).

Ciavatta e Ramos (2011, p. 32) analisam que "os termos educação politécnica e educação tecnológica foram utilizados por Marx para explicitar sua defesa de um ensino que permita a compreensão dos fundamentos técnico-científicos dos processos de produção". O sujeito precisa refletir sobre os meios de produção de forma contextualizada, consciente e crítica para a compreensão reflexiva do trabalho e seu papel cultural e social. Para Ramos (2008), o trabalho compreende o sentido ontológico do ser, a ciência e a cultura.

O trabalho compreendido como realização humana inerente ao ser (sentido ontológico) e como prática econômica (sentido histórico associado ao respectivo modo de produção); a ciência compreendida como os conhecimentos produzidos pela humanidade que possibilita o contraditório avanço produtivo; e a cultura, que corresponde aos valores éticos e estéticos que orientam as normas de conduta de uma sociedade (p. 3).

Dessa forma, o currículo integrado atende aos princípios da Educação Profissional e Tecnológica, quando se pressupõe a construção dos saberes de forma integrada para promover a indissociabilidade entre educação profissional e educação básica. Em meio às possibilidades de operacionalizar o currículo, optamos pela construção colaborativa de um videodocumentário socioambiental, no qual os estudantes puderam participar ativamente, de forma lúdica e criativa. As propostas para o Ensino Médio, conforme as DCNs (BRASIL, 2013), contemplam dois eixos:

Assim, as propostas voltadas para o Ensino Médio, em geral, estão baseadas em metodologias mistas (SANTOMÉ, 1998), as quais são desenvolvidas em, pelo menos, dois espaços e tempos. Um, destinado ao aprofundamento conceitual no interior das disciplinas, e outro, voltado para as denominadas atividades integradoras. É a partir daí que se apresenta uma possibilidade de organização curricular do Ensino Médio, com uma organização por disciplinas (recorte do real para aprofundar 
conceitos) e com atividades integradoras (imersão no real ou sua simulação para compreender a relação parte-totalidade por meio de atividades interdisciplinares) (p. 184).

Assim, para proporcionarmos a consonância do desenvolvimento da pesquisa com as Diretrizes Curriculares Nacionais (BRASIL, 2013), buscamos uma atividade integradora na perspectiva de práticas interdisciplinares enriquecidas com temáticas transversais, a fim de proporcionar conhecimento global na relação parte-totalidade:

A interdisciplinaridade é, portanto, uma abordagem que facilita o exercício da transversalidade, constituindo-se em caminhos facilitadores da integração do processo formativo dos estudantes, pois ainda permite a sua participação na escolha dos temas prioritários. A interdisciplinaridade e a transversalidade complementam-se, ambas rejeitando a concepção de conhecimento que toma a realidade como algo estável, pronto e acabado (BRASIL, 2013, p. 184).

A produção do documentário socioambiental, portanto, trata-se de uma atividade integradora e transversal. Conforme já exposto, as atividades integradoras são previstas nas DCNs (BRASIL, 2013) e se apoiam em práticas interdisciplinares para enriquecer diferentes áreas do conhecimento. Sendo assim, o presente trabalho não se constitui como atividade interdisciplinar com reunião de disciplinas, mas considera possíveis contribuições para as várias áreas do conhecimento.

Para Ramos (2008, p. 20), os conteúdos não constituem fim em si mesmos "nem se limitam a insumos para o desenvolvimento de competências(...)". A função primordial da educação integrada é possibilitar ao sujeito a compreensão da realidade em sua totalidade, compreendendo as partes que a constituem e suas inter-relações: "A compreensão do real como totalidade exige que se conheçam as partes e as relações entre elas, o que nos leva a constituir seções tematizadas da realidade(...)" (RAMOS, 2008, p. 21). Depreendemos, então, a interdisciplinaridade como método possível para promover esta integração, não de forma paralela, mas contextual, abarcando saberes de diferentes áreas científicas para a compreensão de "uma realidade concreta tematizada" (RAMOS, 2008):

(...) o conhecimento não é de coisas, entidades, seres, etc., mas sim das relações que se trata de descobrir, apreender no plano do pensamento. São as apreensões assim elaboradas e formalizadas que constituem a teoria e os conceitos. A Ciência é a parte do conhecimento melhor sistematizado e deliberadamente expresso na forma de conceitos representativos das relações determinadas e apreendidas da realidade considerada. $O$ conhecimento de uma seção da realidade concreta ou a realidade concreta tematizada constitui os campos da ciência (p. 21).

Nesse sentido, o processo de produção coletiva de documentário socioambiental articula-se com a construção de conceitos acerca de uma realidade concreta tematizada, e poderá contribuir para a apreensão do trabalho como princípio educativo na dimensão ontológica do ser social e, segundo a concepção de omnilateralidade, como princípio de formação humana integral. A figura 1 foi adaptada do original para compreensão de que um "fenômeno social possui múltiplas dimensões e a sua compreensão exige que nós o vejamos como totalidade" (RAMOS, 2008, p. 18). 
Figura 1 - Esquema representando o processo de produção colaborativa de documentário socioambiental contextualizado com as dimensões trabalho, ciência e cultura na construção do conhecimento acerca de uma temática

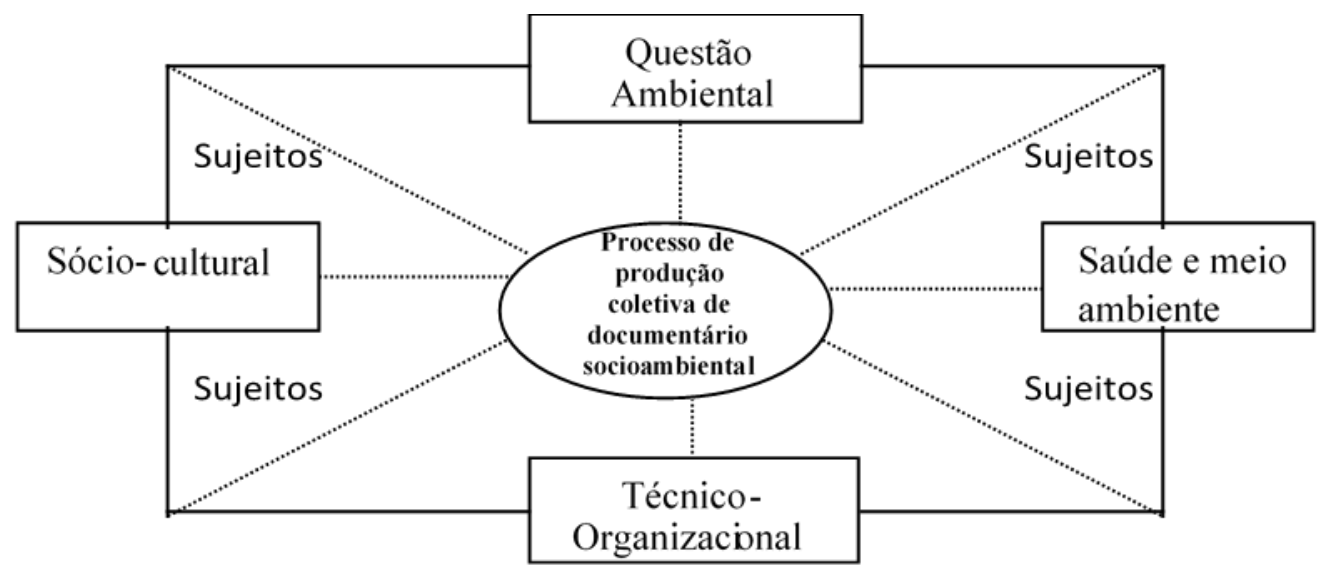

Fonte: RAMOS (2008, p. 18), adaptada pelos autores.

O esquema supra representa a produção coletiva de documentário socioambiental no curso de nível médio Técnico em Controle Ambiental Integrado. A Figura representa, ainda, como ocorrem as contribuições interdisciplinares no documentário e as seguintes inter-relações: a partir da temática socioambiental insere-se a questão ambiental, a área sociocultural, a área técnico organizacional e as áreas saúde e meio ambiente. A produção do documentário propõe: uma temática alvitrada a partir da visão dos educandos sobre a realidade vivenciada; a exploração da questão ambiental a ser estudada e suas questões socioculturais; a identificação dos percalços das problemáticas advindas da questão ambiental trabalhada e seus efeitos na saúde e meio ambiente; e a abrangência das possíveis atuações do profissional técnico.

Observamos que as categorias do esquema anterior estão inter-relacionadas e estabelecem a exploração dos saberes de diversas áreas do conhecimento, em uma interconexão de saberes. Nesse sentido, o processo de construção do documentário integra diferentes saberes e recorre à produção colaborativa de mídia audiovisual como recurso tecnológico potencializador da aprendizagem, o que se configura como uma ferramenta tecnológica com potencial lúdico e criativo para o ensino e aprendizagem. A construção coletiva do documentário socioambiental apoia-se nos "pressupostos do paradigma inovador na ciência" (BEHRENS, 2013).

Os pressupostos do paradigma inovador na ciência propõem movimentos de evolução, de interconexão, de entropia, de inter-relacionamento e defendem um pensamento em rede, tal qual uma teia, onde todos os seres vivos interagem e são interdependentes uns dos outros. Esse movimento originou uma crise de dimensões planetárias, advinda historicamente de um paradigma que permitiu a separação, a divisão, a fragmentação, levando a uma visão mecanicista do mundo. A evolução da ciência para superar o pensamento newtoniano-cartesiano, que propõe a fragmentação, a unicidade, a parte, vem dando lugar a um pensamento holístico, que busca a reunificação das partes no todo (p. 88). 
A partir do exposto, inferimos que a produção coletiva de documentário coopera com o paradigma inovador na ciência, proporcionando um ensino contextual e globalizador, indo ao encontro de uma visão holística:

A visão holística implica pensar coletivamente, uns dependendo do sucesso dos outros, das parcerias, do trabalho coletivo. Portanto, a escola precisa oferecer situações de problematizações, fazendo refletir sobre a realidade, para que os alunos aprendam a administrar conflitos, pensamentos divergentes, respeitar a opinião dos outros, saber contra argumentar sem que esse processo seja de luta, agressão e competitividade (BEHRENS, 2013, p. 88-89).

Para atendimento aos ideais da visão holística, faz-se necessário, então, o ensino contextualizado: "A visão holística busca a perspectiva interdisciplinar, superando a fragmentação, a divisão, a compartimentalização do conhecimento" (BEHRENS, 2013, p. 99). Para exemplificar, o Quadro 1, elaborado pelos autores deste artigo, apresenta as contribuições dos saberes de diferentes áreas para a construção do conhecimento contextual da temática socioambiental, na perspectiva de uma atividade integradora, que utiliza a produção coletiva de videodocumentário como recurso educacional potencializador de aprendizagem.

Quadro 1 - Interconexão de saberes relacionados à temática socioambiental

\begin{tabular}{|c|c|c|c|}
\hline \multicolumn{5}{|c|}{ TEMÁTICA SOCIOAMBIENTAL } \\
\hline Aspectos ambientais & $\begin{array}{c}\text { Aspectos } \\
\text { socioculturais }\end{array}$ & $\begin{array}{c}\text { Aspectos técnico- } \\
\text { organizacionais }\end{array}$ & $\begin{array}{c}\text { Relações com a saúde } \\
\text { e meio ambiente }\end{array}$ \\
\hline $\begin{array}{c}\text { Problemática } \\
\text { socioambiental } \\
\text { observada no IFRJ, } \\
\text { Campus Nilópolis. }\end{array}$ & $\begin{array}{c}\text { Situações } \\
\text { socioculturais } \\
\text { no âmbito da } \\
\text { problemática. }\end{array}$ & $\begin{array}{c}\text { Possibilidades de atuação } \\
\text { do técnico em Controle } \\
\text { Ambiental nos aspectos }\end{array}$ & $\begin{array}{c}\text { Consequências do } \\
\text { problema observado } \\
\text { na saúde e meio } \\
\text { ambiente. }\end{array}$ \\
\hline
\end{tabular}

Fonte: Os autores.

\section{Produção coletiva de documentário como recurso educacional}

Com o advento do YouTube, os jovens interessam-se cada vez mais por criação de vídeos para postagem em seus canais nesta Plataforma. A produção de vídeos na escola proporciona a integração de tecnologias cotidianas ao currículo escolar.

Moletta (2019), em um manual prático para criação de vídeos a baixo custo, considera que "hoje, para produzir um curta-metragem, bastam apenas a criatividade artística, uma câmera de vídeo ou de foto e um computador" (MOLETTA, 2019, p. 11).

Oechsler, Fontes e Borba (2017) abordam o advento dos Youtubers, que arrastam multidões de seguidores e inspiram os jovens a criarem seus vídeos e postarem nesta Plataforma digital. Os autores consideram que a produção de vídeo destaca o protagonismo do aluno e corrobora "a leitura, pesquisa, interpretação, criatividade, escrita, oralidade, assim como permite a criação de um vínculo comunicativo entre professor-aluno" (OECHSLER, FONTES; BORBA, 2017).

Oechsler, Fontes e Borba (2017) ressaltam que as etapas da produção de vídeo podem ser exploradas por diferentes áreas disciplinares: 
Destacamos que a atividade pode ter um caráter interdisciplinar, envolvendo outras matérias e suas leituras do vídeo. Por exemplo, na disciplina de língua portuguesa pode ser explorada a elaboração do roteiro, discutindo-se com os alunos as diversas formas de narrativas. Na disciplina de artes pode-se elaborar uma discussão das técnicas de filmagem e as linguagens visuais do vídeo. São apenas alguns exemplos dentre um campo vasto de possibilidades de trabalho interdisciplinar que virá a complementar e enriquecer o trabalho final.

Compreendemos, dessa forma, que os recursos tecnológicos, amplamente explorados no cotidiano dos alunos, funcionam como aliados ao ensino. A tecnologia integra o dia a dia dos alunos, e o seu uso como recurso educacional favorece o envolvimento discente no processo de aprendizagem. Para Kenski (2012, p. 46), "as novas tecnologias de comunicação e informação (...) dinamizam o espaço de ensino-aprendizagem, onde, anteriormente, predominava a lousa, o giz, o livro e a voz do professor". Cabe ressaltar que as Tecnologias de Informação e Comunicação (TICS) não são apenas recursos didáticos; elas devem ser planejadas e operacionalizadas pedagogicamente (KENSKI, 2012); logo, a mídia educacional pressupõe um planejamento intencional para o desenvolvimento da prática pedagógica.

Por conseguinte, o uso de documentários socioambientais na educação contribui para a inserção da cultura midiática no processo educacional, constitui uma ferramenta tecnológica de aprendizagem e integra a política pública de comunicação para a Educação Ambiental (Lei Federal 9.795, de 1999). Para instituição dessa linha de ação, criou-se o campo de conhecimento intitulado Educomunicação Socioambiental, que pode ser definido como:

Conjunto de ações e valores que correspondem à dimensão pedagógica dos processos comunicativos ambientais, marcados pelo dialogismo, pela participação e pelo trabalho coletivo. A indissociabilidade entre questões sociais e ambientais no fazer-pensar dos atos educativos e comunicativos é ressaltada pelo termo socioambiental. A dimensão pedagógica, nesse caso em particular, tem foco no "como" se gera os saberes e "o que" se aprende na produção cultural, na interação social e com a natureza (BRASIL, 2008).

A análise das contribuições da produção de documentários ambientais na formação de estudantes do curso de Gestão Ambiental no Cefet/RJ, realizada por Rocha e Mattos (2014), demonstra que o processo contribuiu para a formação dos discentes:

Dentre eles destacam-se a possibilidade de articular o conhecimento adquirido na graduação com a realidade socioambiental e o fato da produção dos vídeos proporcionar a oportunidade de desenvolverem um trabalho em equipe. Além disso, consideram que este material possui um relevante potencial didático para atividades de Educação Ambiental em espaços formais e não formais de ensino (p. 9).

Perante o exposto, a produção coletiva de documentário socioambiental proporciona, em consonância com os princípios curriculares, a integração da tecnologia no ensino, de forma lúdica, criativa e com efetiva aprendizagem.

\section{Projeto de trabalho: estrutura do documentário}

O documentário constitui-se em um processo criativo, "marcado por várias etapas de seleção", com escolhas que orientam "uma série de recortes (...) que marcam a apropriação do real por um discurso" (SOARES, 2007, p. 20). Dessa forma, a representação do real ocorre gradualmente. 
Se no filme de fiç̧ão o controle do universo de representação está, desde a saída, todo à mão dos responsáveis pela concepção do filme, seja ele uma adaptação ou não, em documentário esse controle é uma aquisição gradual. Parte-se necessariamente de uma busca àquilo que é externo ao cineasta. Essa busca envolve, necessariamente, uma negociação prévia, para a viabilização do registro, que marca o início de um processo de troca entre um "eu" e um "outro" (SOARES, 2007, p. 21).

Soares (2007) analisa que na pré-produção do documentário alguns elementos são necessários, no entanto a organização é variável, conforme a proposta pretendida. O primeiro elemento da pré-produção é a pesquisa do assunto que será abordado para aprofundamento do tema (SOARES, 2007). Com o texto da pesquisa, buscam-se outras informações e ajuste do conteúdo "ao formato discursivo de um filme" (SOARES, 2007, p. 84). Durante as pesquisas estabelecem-se as hipóteses para o documentário, as quais conduzirão o projeto. As fontes de pesquisa são diversas e podem ser utilizados(as): "material impresso; material de arquivo (filmes, fotos, arquivos de som); entrevistas; pesquisa de campo (...)" (SOARES, 2007, p. 85). Durante a pré-produção, define-se os elementos: argumento, personagens, tempo histórico, tempo narrativo, espaço e estrutura discursiva.

Os personagens, nesse estudo, foram colocados em situação de depoentes, sustentando a estrutura discursiva narrativa do documentário (SOARES, 2007). O tempo histórico demonstrou, no presente trabalho, uma situação atual, e o IFRJ configurou o espaço onde ocorreram os eventos desenrolados no desenvolvimento do Documentário. A estrutura discursiva do Documentário, neste trabalho, seguiu a sequência: "Início: Apresentação do assunto (...) Meio: desenvolvimento do assunto (...) Fim: resolução do assunto" (SOARES, 2007, p. 113-121). Cabe ressaltar que o desenvolvimento do assunto buscou construir a temática apresentada, e a sua resolução não representou necessariamente uma ação conclusiva, mas sim, propostas possíveis para solucionar as indagações apresentadas no argumento. A organização das sequências no tratamento/escaleta considerou o encadeamento de ideias para a construção do Documentário, com a escrita das sequências resumindo as narrativas:

Em decorrência dessa maior diversidade do repertório de imagens e sons, a escrita do tratamento passa a ser feita a partir do resumo das seqüências de planos, e não das cenas dramáticas. $O$ resumo dessas seqüências pode conter uma informação narrativa, da mesma maneira que no tratamento do roteiro de ficção, mas pode também expressar uma ideia, um argumento ou uma descrição" (SOARES, 2007, p. 132).

Iniciamos, então, o roteiro com a definição do tema, em seguida a apresentação do assunto, após o desenvolvimento e, por fim, a exposição de alternativas para resolução dos conflitos abordados. Um roteiro de documentário "é a marca no papel desse esforço de aquisição de controle de um universo externo, da remodelação de um real nem sempre prenhe de sentido" (SOARES, 2007, p. 21). Documentários socioambientais retratam a realidade de conflitos sociais no meio ambiente. A proposta de produção colaborativa de documentário na educação apresenta uma estratégia para trabalhar temas ambientais de forma lúdica e contextual. É importante reforçar o compromisso dessa estratégia pedagógica com a verdade:

Dentro do universo dos recursos audiovisuais, os documentários têm esse potencial de estabelecimento de diálogos reforçado por conta de seu compromisso com a realidade. Diferente do cinema (que pode ser uma obra de ficção, ainda que o en- 
redo se desenvolva inspirado em um fato real), os documentários possuem o compromisso de relato fiel da realidade. Sendo assim, possuem um enorme potencial como instrumento da Educação Ambiental, pois podem levar informação e estímulo a reflexão por meio de uma realidade documentada (MENDES; ROCHA, 2015, p. 3).

Para a produção do documentário, observamos a preeminência de um Projeto de Trabalho organizado intencionalmente, uma vez que se trata de atividade com fins educacionais, compondo, assim, o Plano de Realização.

Hernández e Ventura (2017) destacam que um Projeto tem como função colaborar para "a criação de estratégias de organização dos conhecimentos escolares em relação ao tratamento da informação e à relação entre os diferentes conteúdos em torno de problemas ou hipóteses(...)" (p. 59).

A organização do projeto, a partir de um eixo temático, articula informações requeridas para o tratamento do tema de estudo com as estratégias para o desenvolvimento, ordenação, compreensão e assimilação pelos discentes (HERNÁNDEZ; VENTURA, 2017). Com isso, a escolha do tema é o fio condutor do projeto. Em torno do tema, conceitos de diferentes áreas científicas podem ser abordados, quando se estabelece a interconexão de saberes. As questões socioambientais são amplas e, para delimitá-las, considerou-se a percepção dos alunos no âmbito do IFRJ/Nilópolis.

Nesse sentido, a escolha da temática socioambiental está relacionada ao perfil do egresso, público-alvo da pesquisa. Contribuíram para esta reflexão considerações sobre a compreensão do homem acerca das relações interdependentes com a natureza e o modo de pensar e fazer Educação Ambiental. A partir da ruptura de dissociações entre homem-meio ambiente e o olhar voltado para a integração, o ambiente é lido em sua totalidade, considerando suas articulações, desdobramentos e consequências.

Grün (2012) reflete sobre o modelo proposto por Descartes, que permeia o conhecimento científico, a posteriori; proporciona uma visão naturalizada do meio ambiente e não contempla questões socioeconômicas e urbanas; "nesta noção "naturalizada", o meio ambiente é a mata, o bosque, a selva, etc. Partindo de uma noção como essa, grandes cidades não têm "meio ambiente". Não faz sentido a noção de que exista um “meio ambiente urbano" (GRÜN, 2012, p. 57). Para Grün (2012):

O processo de objetificação implica simultaneamente domínio, posse, mas também perda, afastamento da natureza. Em um sentido que se aproxima bastante de Freud, a natureza torna-se o "recalcado", aquilo que está "lá", sabemos disso, mas criamos mecanismos para que isso não venha à tona. A natureza é puro horror. Nós somos humanos, civilizados, distantes do "horror" da barbárie do ld. Este é o destino da natureza dominada da qual nos distanciamos (p. 36).

Dessa forma, grandes eventos, ${ }^{3}$ provenientes de movimentos políticos e sociais, contribuíram efetivamente para a Educação Ambiental Crítica, que articula o meio ambiente com as questões sociais, econômicas, políticas e culturais.

A partir da Conferência de Estocolmo, em 1996, outros encontros foram realizados. Para ver mais consultar: DIAS, Genebaldo Freire. Educação ambiental: princípios e práticas. 9. ed. São Paulo: Gaia, 2004. p. 101-200. 
Para Hernández e Ventura (2017), após a delimitação do tema, deve-se proceder a escolha dos conteúdos, atividades e pesquisa de fontes de informações que possibilitem o início e o desenvolvimento do Projeto. Faz-se necessário, ainda, oportunizar aos alunos novos conhecimentos e diferentes conexões, assim como, proporcionar "um clima de envolvimento e de interesse no grupo" (HERNÁNDEZ; VENTURA, 2017, p. 67). Contribuem, além disso, para a organização do Projeto, a previsão dos recursos e o planejamento alicerçado em uma sequência avaliativa:

Inicial: o que os alunos sabem sobre o tema, quais são suas hipóteses e referências de aprendizagem; Formativa: o que estão aprendendo, como estão acompanhando o sentido do Projeto; Final: o que aprenderam em relação às propostas iniciais? São capazes de estabelecer novas relações? (HERNÁNDEZ; VENTURA, 2017, p. 67).

Dentro dessa conjuntura, para a finalização do Projeto, temos a recapitulação do processo "em forma de programação a posteriori, que possa ser utilizada como memória (...)" (HERNÁNDEZ; VENTURA, 2017, p. 68).

Após as etapas de pré-produção e construção do roteiro, ainda em conformidade com o Projeto de Trabalho delineado, têm-se o processo de filmagem, que envolve o conhecimento de algumas técnicas básicas para captação das imagens, como os planos utilizados, os enquadramentos e alguns recursos para estabilização da imagem e meIhora do som. Por fim, a pós-produção, ainda que não seja realizada pelos idealizadores do Documentário, sugere um roteiro de edição para orientar o trabalho do editor de imagens.

\section{METODOLOGIA}

\section{Contexto da pesquisa}

Realizamos a pesquisa na região da Baixada Fluminense, município de Nilópolis, no IFRJ, Campus Nilópolis. Os sujeitos da pesquisa foram discentes do curso Técnico em Controle Ambiental Integrado. O recorte amostral considerou o perfil do egresso do curso, e as questões relacionadas ao meio ambiente e sociedade integram a formação do profissional. A escolha dos participantes da pesquisa considerou os alunos matriculados no curso Técnico em Controle Ambiental Integrado, tendo em vista que a questão investigativa foi direcionada aos discentes em processo de formação no referido curso. Sendo assim, organizamos um curso de Extensão, aprovado em edital interno do IFRJ, Campus Nilópolis - em parceria com a Coordenação de Extensão (Coex) - para o desenvolvimento das oficinas de produção do videodocumentário socioambiental. Para tal, tínhamos como pré-requisito, no período de inscrições, os alunos matriculados no curso Técnico em Controle Ambiental Integrado, e disponibilizamos 15 vagas a serem preenchidas de forma voluntária, dentro do perfil aqui descrito. No total, nove alunos interessaram-se, realizaram a inscrição e participaram deste projeto de pesquisa.

A pesquisa contribuiu para a reflexão crítica dos discentes em processo de formação acerca da temática socioambiental, e foi submetida e avaliada pelo Comitê de Ética em Pesquisa do IFRJ, com aprovação de Parecer sob o no 3.386.362. 


\section{Estrutura metodológica}

Empregamos a abordagem qualitativa, em interlocução com os sujeitos, do tipo: Pesquisa Participante; relação sujeito-sujeito; e, quanto ao objetivo, é interpretativa. A pesquisa qualitativa, para Minayo (2010, p. 21-22),

(...) trabalha com o universo de significados, motivos, aspirações, crenças, valores e atitudes, o que corresponde a um espaço mais profundo das relações, dos processos e dos fenômenos que não podem ser reduzidos à operacionalização de variáveis.

A pesquisa participante, segundo Severino (2016, p. 126), configura-se como aquela que "compartilha a vivência dos sujeitos pesquisados, participando de forma sistemática e permanente, ao longo do tempo da pesquisa, das suas atividades." Corroborando essa visão, Guy Le Boterf (1984, p. 52) analisa que:

Considerando as limitações da pesquisa tradicional, a pesquisa participante vai, ao contrário, procurar auxiliar a população envolvida a identificar por si mesma os seus problemas, a realizar a análise crítica destes e a buscar as soluções adequadas. Deste modo, a seleção dos problemas a serem estudados emerge da população envolvida, que os discute com especialistas apropriados, não emergindo apenas da simples decisão dos pesquisadores.

Guy Le Boterf (1984, p. 52), em sua proposta de modelo de pesquisa participante, propõe um método adaptável "a cada projeto específico", organizado em quatro fases:

Primeira fase: A montagem institucional e metodológica da pesquisa participante; Segunda fase: $O$ estudo preliminar e provisório da região e da população envolvidas; Terceira fase: A análise crítica dos problemas que a população considera prioritários e que seus membros (organizados em grupos de estudo) desejam estudar e resolver; Quarta fase: A programação e a aplicação de um plano de ação (incluindo atividades educacionais) que contribuam para a solução os problemas encontrados (p. 53).

Para alcançarmos os objetivos propostos na pesquisa, seguimos o método de Guy Le Boterf (1984), conforme discriminado anteriormente, sendo este adaptado à pesquisa em tela:

Quadro 2 - Esquema demonstrativo da estrutura ou etapas da pesquisa

\begin{tabular}{|c|c|}
\hline Etapas da pesquisa & Descrição das atividades desenvolvidas nas etapas da pesquisa \\
\hline $\begin{array}{c}\text { Montagem } \\
\text { institucional e } \\
\text { metodológica } \\
\text { da Pesquisa } \\
\text { Participante: }\end{array}$ & $\begin{array}{l}\text { - Definição do quadro teórico: estrutura da pesquisa; elaboração de um } \\
\text { Projeto de Curso de Extensão intitulado "Oficinas de produção de vídeo } \\
\text { documentário socioambiental", em formato de oficinas - que foram } \\
\text { realizadas em sete sábados, com duração de } 3 \text { horas; } \\
\text { - Delimitação da região a ser estudada: IFRJ, Campus Nilópolis; } \\
\text { - Divulgação do curso de Extensão e inscrição on-line no site da Coex/IFRJ, } \\
\text { - Campus Nilópolis; } \\
\text { - Levantamento de conhecimentos prévios relacionados às questões } \\
\text { ambientais, com auxílio de instrumento de coleta de dados - mapa mental } \\
\text { pré-elaborado e tour institucional para fotografias e gravação de vídeos; } \\
\text { - Seleção e formação do grupo de pesquisa: alunos inscritos no curso de } \\
\text { - Extensão totalizaram nove participantes; } \\
\text { Organização do processo de pesquisa participante: apresentação do curso } \\
\text { de Extensão e sua relação com a pesquisa em tela. }\end{array}$ \\
\hline
\end{tabular}




\begin{tabular}{|c|c|}
\hline $\begin{array}{l}\text { Estudo preliminar e } \\
\text { provisório }\end{array}$ & $\begin{array}{l}\text { - Descoberta do universo vivido pelos pesquisados - percepção prévia dos } \\
\text { sujeitos da pesquisa; discussões acerca das possíveis temáticas para o } \\
\text { documentário: "Quais as percepções destes sobre tais situações? Quais } \\
\text { as ações possíveis?" }\end{array}$ \\
\hline $\begin{array}{l}\text { Análise dos } \\
\text { problemas }\end{array}$ & $\begin{array}{l}\text { - } \quad \text { Formulação e análise do problema-cenário, fatos, hipóteses e deficiências; } \\
\text { - Estudo autodirigido - novas informações em relação ao objeto de estudo } \\
\text { e definição de estratégias; } \\
\text { - } \quad \text { Exposição oral do estudo realizado. }\end{array}$ \\
\hline $\begin{array}{l}\text { Programação } \\
\text { e execução do } \\
\text { Roteiro }\end{array}$ & 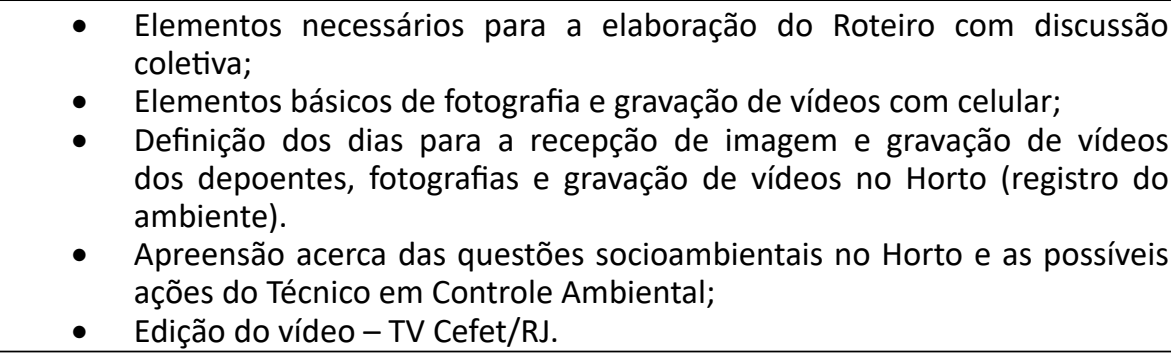 \\
\hline $\begin{array}{l}\text { Divulgação e } \\
\text { orientação para } \\
\text { replicabilidade } \\
\text { do Produto } \\
\text { Educacional }\end{array}$ & $\begin{array}{l}\text { Construção de um mural virtual com a utilização da ferramenta tecnológica } \\
\text { Padlet, para a exposição do videodocumentário, do projeto de curso de extensão, } \\
\text { dos materiais utilizados nas oficinas e do roteiro final construído coletivamente; } \\
\text { O Padlet é uma ferramenta tecnológica, disponibilizada de forma on-line, que } \\
\text { possibilita a criação de murais virtuais interativos, onde podem ser inseridos e } \\
\text { compartilhados diferentes conteúdos multimídia. Site para acesso: https://pt-br. } \\
\text { padlet.com/barbara16ifrj/8lj958jyag76 } \\
\text { Divulgação do videodocumentário na plataforma YouTube. }\end{array}$ \\
\hline
\end{tabular}

Fonte: Os autores.

\section{Instrumentos de coleta de dados}

Para o levantamento de dados da pesquisa foram utilizados os seguintes procedimentos: mapa mental pré-elaborado, registro das problemáticas socioambientais identificadas no campus em fotografias e vídeos (participantes), estudo autodirigido, estudo coletivo e avaliação com respostas discursivas (Quadro3).

Quadro 3 -Instrumentos de coleta dos dados e atividades desenvolvidas por oficina

\begin{tabular}{|c|c|c|c|}
\hline OFICINAS & $\begin{array}{l}\text { INSTRUMENTOS } \\
\text { DE COLETA DE } \\
\text { DADOS }\end{array}$ & $\begin{array}{c}\text { COLETA DE } \\
\text { DADOS }\end{array}$ & ATIVIDADES DESENVOLVIDAS \\
\hline $1 \underline{a}$ & $\begin{array}{l}\text { Mapa conceitual } \\
\text { pré-elaborado } \\
\text { - itens para } \\
\text { conceituação: } \\
\text { argumento, tema, } \\
\text { apresentação } \\
\text { do assunto, } \\
\text { desenvolvimento } \\
\text { e resolução; } \\
\text { registro de } \\
\text { problemáticas } \\
\text { ambientais no } \\
\text { campus por meio } \\
\text { de fotografias } \\
\text { e vídeos, com } \\
\text { utilização de } \\
\text { celular. }\end{array}$ & $\begin{array}{c}\text { Produção } \\
\text { escrita dos } \\
\text { participantes; } \\
\text { registros visuais } \\
\text { (fotografias) e } \\
\text { audiovisuais } \\
\text { (vídeos) } \\
\text { realizados pelos } \\
\text { participantes. }\end{array}$ & $\begin{array}{l}\text { (PERCEPÇÕES PRÉVIAS) Apresentou-se o curso de } \\
\text { Extensão aos participantes, com subsídios para a } \\
\text { elaboração de um roteiro. Conversou-se brevemente } \\
\text { sobre as possíveis questões socioambientais e, } \\
\text { em seguida, os estudantes, com o propósito de } \\
\text { identificarem essas questões no campus, realizaram } \\
\text { um tour institucional com registro em fotografias } \\
\text { e vídeos nos seus celulares. As mídias foram } \\
\text { enviadas para um grupo construído em Rede Social } \\
\text { WhatsApp. Após, retornaram para o local das } \\
\text { oficinas, uma sala de aula localizada no interior do } \\
\text { campus. Formaram-se três grupos para a construção } \\
\text { de um mapa conceitual pré-elaborado, no qual } \\
\text { registraram as percepções prévias socioambientais } \\
\text { em consonância com a abordagem realizada } \\
\text { anteriormente sobre as etapas de construção de } \\
\text { um roteiro. Em sequência, apresentou-se o mapa } \\
\text { conceitual por um representante de cada grupo e se } \\
\text { discutiu as possíveis temáticas para o documentário. }\end{array}$ \\
\hline
\end{tabular}


Produção de Documentário Socioambiental:

\begin{tabular}{|c|c|c|c|}
\hline $2^{\mathrm{a}}$ & $\begin{array}{l}\text { Estudo } \\
\text { autodirigido. }\end{array}$ & $\begin{array}{l}\text { Produção } \\
\text { escrita dos } \\
\text { participantes; } \\
\text { observação dos } \\
\text { pesquisadores. }\end{array}$ & $\begin{array}{c}\text { Formulação da problemática socioambiental; causas } \\
\text { da problemática socioambiental; novas informações } \\
\text { e definição de estratégias acerca da problemática } \\
\text { socioambiental. }\end{array}$ \\
\hline 3a & $\begin{array}{l}\text { Estudo coletivo } \\
\text { com roteiro } \\
\text { norteador. }\end{array}$ & $\begin{array}{l}\text { Produção } \\
\text { escrita dos } \\
\text { participantes; } \\
\text { observação dos } \\
\text { pesquisadores. }\end{array}$ & $\begin{array}{l}\text { Discussão coletiva para identificação das atribuições } \\
\text { do Técnico em Controle Ambiental, em consonância } \\
\text { com o tema definido pelo grupo; possibilidades } \\
\text { de atuação do Técnico em Controle Ambiental no } \\
\text { âmbito das atribuições identificadas na discussão } \\
\text { coletiva. }\end{array}$ \\
\hline 4a & $\begin{array}{l}\text { Discussão } \\
\text { coletiva. }\end{array}$ & $\begin{array}{c}\text { Produção } \\
\text { escrita dos } \\
\text { participantes; } \\
\text { observação dos } \\
\text { pesquisadores. }\end{array}$ & $\begin{array}{c}\text { Definição dos elementos necessários para a } \\
\text { elaboração do Roteiro, com discussão coletiva e } \\
\text { sistematização. }\end{array}$ \\
\hline 5 a & $\begin{array}{l}\text { Exposição oral e } \\
\text { interativa }\end{array}$ & $\begin{array}{l}\text { Observação dos } \\
\text { pesquisadores. }\end{array}$ & $\begin{array}{c}\text { Apresentação dos elementos básicos de fotografia e } \\
\text { de gravação de vídeos com celular para uma imagem } \\
\text { minimamente aceitável. }\end{array}$ \\
\hline 6a & \begin{tabular}{|l|} 
Saída de campo: \\
fotografia e \\
gravação de \\
vídeos do \\
ambiente; captura \\
dos depoimentos.
\end{tabular} & $\begin{array}{l}\text { Registros visuais } \\
\text { (fotografias) e } \\
\text { audiovisuais } \\
\text { (vídeos) } \\
\text { realizados pelos } \\
\text { participantes; } \\
\text { observação dos } \\
\text { pesquisadores. }\end{array}$ & $\begin{array}{l}\text { Utilizou-se diferentes dias para recepção de } \\
\text { imagem e gravação de vídeos dos depoentes que } \\
\text { não estariam na Instituição no dia previsto, um } \\
\text { sábado. Decorreu no sábado previsto as fotografias e } \\
\text { gravação de vídeos no Horto (registro do ambiente). }\end{array}$ \\
\hline 7ạ & $\begin{array}{l}\text { Avaliação } \\
\text { discursiva. }\end{array}$ & $\begin{array}{l}\text { Produção } \\
\text { escrita dos } \\
\text { participantes. }\end{array}$ & $\begin{array}{l}\text { Revisão das questões socioambientais no Horto e as } \\
\text { possíveis ações do técnico em Controle Ambiental, a } \\
\text { partir das abordagens realizadas nas oficinas. }\end{array}$ \\
\hline
\end{tabular}

Fonte: Os autores.

\section{ANÁLISE DE DADOS}

A análise de dados apoiou-se na Análise de Conteúdo de Bardin (2002), entendendo que: "as diferentes fases da análise de conteúdo (...) organizam-se em torno de três pólos cronológicos: 1) a pré-análise; 2) a exploração do material; 3) o tratamento dos resultados, a inferência e a interpretação" (p. 95). Para analisar os dados obtidos no processo de construção do Produto Educacional, organizou-se a relação: oficina-proposições-abordagens teóricas envolvidas (Quadro 4). Ante o exposto, aliou-se o desenvolvimento do Produto Educacional com a fundamentação teórica da pesquisa.

Quadro 4 - Títulos, proposições e abordagens teóricas envolvidas nas oficinas

\begin{tabular}{|c|c|c|}
\hline OFICINA & PROPOSIÇÕES & ABORDAGENS TEÓRICAS ENVOLVIDAS \\
\hline $\begin{array}{l}\text { 1a - Percepções } \\
\text { prévias }\end{array}$ & $\begin{array}{|lrr|}\text { Visão desconexa e pouco } \\
\text { interconectada entre } & \text { os } \\
\text { elementos constituintes } & \text { da } \\
\text { problemática do Horto. } & \end{array}$ & $\begin{array}{l}\text { Conhecimento das partes e suas relações } \\
\text { entre elas para a compreensão do real em sua } \\
\text { totalidade (RAMOS 2008). }\end{array}$ \\
\hline $\begin{array}{l}2 \text { a - Formulação } \\
\text { e reformulação } \\
\text { da problemática } \\
\text { socioambiental }\end{array}$ & $\begin{array}{l}\text { Estabelecimento de relações } \\
\text { entre o conhecimento prévio } \\
\text { e o estudo autodirigido para } \\
\text { aquisição de novas informações; } \\
\text { descobertas das interconexões a } \\
\text { partir do roteiro de estudo. }\end{array}$ & $\begin{array}{l}\text { Visão holística: pensar coletivamente trabalho } \\
\text { coletivo (BEHRENS, 2013); } \\
\text { Visão naturalizada do meio ambiente que } \\
\text { implica no processo de objetificação da } \\
\text { natureza (GRÜN, 2012). }\end{array}$ \\
\hline
\end{tabular}




\begin{tabular}{|c|c|c|}
\hline $\begin{array}{l}\text { 3a - Identificação } \\
\text { das atribuições } \\
\text { do Técnico em } \\
\text { Controle Ambiental } \\
\text { e possibilidades de } \\
\text { atuação dentro da } \\
\text { temática definida }\end{array}$ & $\begin{array}{l}\text { Compreensão da relação } \\
\text { profissional do Técnico em } \\
\text { Controle Ambiental nas questões } \\
\text { socioambientais. }\end{array}$ & $\begin{array}{l}\text { Atividades integradoras DCNs (BRASIL, 2013); } \\
\text { compreensão global da realidade e suas inter- } \\
\text { relações (RAMOS, 2008); protagonismo do } \\
\text { aluno na produção de vídeo; contribuição na } \\
\text { leitura, escrita e exposição oral (OECHSLER; } \\
\text { FONTES; BORBA, 2017). }\end{array}$ \\
\hline $\begin{array}{l}\text { 4a - Elementos para } \\
\text { a construção do } \\
\text { Roteiro }\end{array}$ & $\begin{array}{l}\text { A partir das relações estabelecidas } \\
\text { e da orientação acerca da } \\
\text { construção de um roteiro, foi } \\
\text { possível, por meio de discussão } \\
\text { coletiva, estabelecer a sequência } \\
\text { das cenas para organização do } \\
\text { roteiro. }\end{array}$ & $\begin{array}{l}\text { Projeto de trabalho (HERNÁNDEZ; VENTURA, } \\
\text { 2017); } \\
\text { Pré-produção, produção e pós-produção } \\
\text { (SOARES, 2007). }\end{array}$ \\
\hline $\begin{array}{l}\text { 5a - Noções de } \\
\text { enquadramento e } \\
\text { gravação de vídeo }\end{array}$ & $\begin{array}{l}\text { Preparação técnica para a } \\
\text { execução do roteiro }\end{array}$ & $\begin{array}{l}\text { Criação de vídeos a baixo custo (MOLETTA, } \\
\text { 2019). }\end{array}$ \\
\hline $\begin{array}{l}\text { 6a - Fotografia do } \\
\text { ambiente, gravação } \\
\text { de vídeos do } \\
\text { ambiente, gravação } \\
\text { dos depoimentos } \\
\end{array}$ & Execução do roteiro & $\begin{array}{l}\text { Uso das TICS de forma planejada e } \\
\text { operacionalizada pedagogicamente (KENSKI, } \\
2012 \text { ). }\end{array}$ \\
\hline $\begin{array}{l}\text { 7ạ - Recapitulação } \\
\text { das questões } \\
\text { socioambientais no } \\
\text { Horto e possíveis } \\
\text { ações do Técnico em } \\
\text { Controle Ambiental }\end{array}$ & $\begin{array}{l}\text { Avaliação discursiva com revisão } \\
\text { dos aspectos abordados nas } \\
\text { oficinas, quando se percebeu } \\
\text { melhor compreensão contextual } \\
\text { e interconexão de saberes. }\end{array}$ & $\begin{array}{l}\text { Atividades integradoras - DCNs (BRASIL, } \\
\text { 2013); compreensão de uma realidade } \\
\text { concreta tematizada (RAMOS, 2008). }\end{array}$ \\
\hline
\end{tabular}

Fonte: Os autores.

\section{RESULTADOS E DISCUSSÃO}

Para a primeira oficina referimos as percepções prévias dos participantes acerca da identificação de questões socioambientais. O Grupo 1 apresentou preocupação com a falta de cuidados no Horto, no entanto sem identificar os elementos que contribuíam para a "precariedade do Horto", conforme registraram. Relataram alguns elementos sociais inter-relacionados, como a falta de segurança e desrespeito no local. Colocaram, ainda, como problema, o vazamento da caixa d'água localizada no Horto. Durante a exposição oral do Grupo 1, os estudantes explicaram que a falta de segurança se relacionava aos objetos pontiagudos descartados no lugar, e em relação ao desrespeito relataram a questão dos lixos despejados no ambiente de forma indevida. Sobre o vazamento da caixa d'água, expuseram a questão do desperdício de água. Como possíveis ações, apresentaram soluções gerais e pertinentes, com o registro de "alertar e informar sobre o estado do Horto", porém não descreveram ações específicas para alcançar as resoluções expostas. Consideraram que o documentário será essencial para a "demonstração dos problemas" e informação da situação do Horto. Em tom imperativo, descreveram como uma das ações "exigir atenção", e finalizaram com a proposição de "aguardar mudanças". Durante a exposição oral, explicaram que o Horto precisa da atenção de toda a comunidade do IFRJ/Nilópolis. Expuseram, com mais ênfase, o vazamento na caixa d'água e o desperdício de água. Mostraram-se indignados com a atitude das pessoas ao jogarem guimbas de cigarro no local indiscriminadamente. 
O Grupo 2 identificou como problemática a "Estação de Tratamento de Água e a importância do tratamento", mas não deliberaram sobre as questões sociais associadas. Durante a exposição oral, relataram que ela se encontra em obras e não funciona. Nas ações possíveis, entenderam como importante identificar as consequências da falta de funcionamento da Estação. Solicitamos aos alunos deste grupo que pesquisassem durante a semana sobre a situação da Estação e sua função.

O Grupo 3 identificou duas situações como questão socioambiental: "a importância do Horto e da Estação de Tratamento", no entanto colocaram alguns elementos sociais em relação ao Horto, como a água acumulada formando poças d'água, proveniente do vazamento da caixa d'água, e o acúmulo de lixo no local, porém a Estação de Tratamento foi abordada de forma geral. Entenderam como necessária a conscientização nos cuidados com o Horto e Estação de Tratamento, entretanto não descreveram como seria realizada uma ação de conscientização.

Em consonância com os dados ponderados, Ramos (2008, p. 21) contribui para a análise das percepções prévias dos alunos, uma vez que a autora nos chama a atenção para a importância de a educação integrada proporcionar "a compreensão da realidade em sua totalidade". Os alunos demonstraram conhecimento em relação à problemática socioambiental, no entanto não estabeleceram relações de causalidade, o que corrobora um ensino compartimentado em detrimento da contextualização do conhecimento.

Para a segunda oficina pretendíamos a reformulação da percepção inicial dos alunos e a aquisição de novas informações com fundamentação teórica. Os participantes realizaram uma sequência de análise da problemática socioambiental identificada, formulando, identificando as causas, pesquisando novas informações em relação ao objeto de estudo e definindo estratégias, em grupo, no formato de estudo autodirigido. Após o levantamento de informações, expuseram oralmente suas descobertas em discussão coletiva, para a sistematização do estudo e definição da temática a ser explorada no documentário. Os grupos reformularam as questões iniciais inter-relacionando o tema ambiental com a comunidade institucional.

O Grupo 1 assimilou com clareza as ocorrências no Horto e suas principais consequências. Apresentaram uma relação de atividades práticas que poderiam ser planejadas para a sensibilização da comunidade institucional, como a confecção de placas artesanais informativas sobre o despejo de lixo no local e fixação no ambiente, instalação de equipamentos para a prevenção de incêndios; irrigação constante do solo para a prevenção de incêndios; remoção da água acumulada; e realização de atividades que levem os alunos a se envolverem e participarem diretamente com o Horto. Compreenderam a prerrogativa de levar alguns fatos a outras instâncias para resolução, como o monitoramento da caixa d'água e a aquisição de equipamentos de prevenção de incêndios. O Grupo 2 não apresentou os dados solicitados na oficina anterior referentes à situação atual da Estação de Tratamento, então a formulação foi hipotética. As novas informações basearam-se no material teórico pesquisado pelo Grupo, mas não têm associação real com o problema de estudo, porquanto não apresentavam informações suficientes. O Grupo 3, com a questão do Horto e da Estação de Tratamento, conseguiu deliberar 
fatores socioambientais em relação ao Horto, o que não ocorreu com a Estação de Tratamento. Apresentaram informações que podem ser acrescidas às do Grupo 1, como o reflorestamento e a infertilidade do solo em decorrência do acúmulo de água, assim como a proliferação de mosquitos, incorrendo em doenças.

Os Grupos 1 e 3 chamaram a atenção para a necessidade de envolvimento da comunidade no Horto como estratégia para a problemática identificada. Durante a exposição oral, os grupos discorreram sobre as suas análises, e algumas inferências foram realizadas para contribuir com a compreensão em relação ao meio ambiente e à sociedade (Figura 2). Diante das discussões realizadas, definimos a temática do Documentário: “O Horto e as questões socioambientais - diálogos possíveis".

Sendo assim, Behrens (2013, p. 88-89) nos auxilia na compreensão da importância do trabalho coletivo e do pensar coletivamente refletindo sobre a realidade para uma visão holística. Para pensar a questão socioambiental por si própria, Grün (2012) fornece elementos importantes quando se refere ao meio ambiente pensando o modelo científico de Descartes, que corrobora uma visão naturalizada do meio ambiente e o distanciamento do homem da natureza, quando o homem não é parte integrante do meio ambiente, o que implica, dessa forma, o processo de objetificação. Quanto mais o homem afasta-se da natureza, mais se perde a noção de ética ao lidar com o meio ambiente.

Para a terceira oficina foi utilizado como material de apoio para o desenvolvimento da atividade o Projeto Pedagógico do curso Técnico em Controle Ambiental do Instituto Federal de Educação, Ciência e Tecnologia do Tocantins - Ifto -, uma vez que o curso Técnico em Controle Ambiental do IFRJ ainda não tem Projeto Pedagógico de curso, pois o mesmo encontra-se em fase de construção, com Grupo de Trabalho (GT) constituído, do qual a pesquisadora é integrante.

Dividimos essa oficina em dois momentos: no primeiro, apresentamos aos participantes todas as atribuições do Técnico em Controle Ambiental e dialogamos sobre cada uma delas. Identificamos as atribuições em correlação com a atuação no Horto: quais foram e levantamento ambiental; medidas para minimização dos impactos ambientais; e campanhas de educação ambiental. Após, no segundo momento, os participantes discorreram, no estudo coletivo, sobre as possibilidades de atuação do Técnico em Controle Ambiental na problemática socioambiental do Horto, e expuseram suas colocações. Ao explorarem sobre o levantamento ambiental, observamos a inter-relação de elementos ambientais do Horto com a comunidade institucional, quando relacionaram a água da caixa d'água que cai sobre o Horto com impactos no solo e, consequentemente, na vegetação, além da formação de poças que podem se tornar focos de doenças como dengue, malária, etc., e a conscientização sobre o lixo jogado incorretamente no local, o que poderia ser mais bem definido conforme mostra a Figura 2: 
Figura 2 - Esquema que demonstra o levantamento ambiental redefinido a partir da análise das oficinas

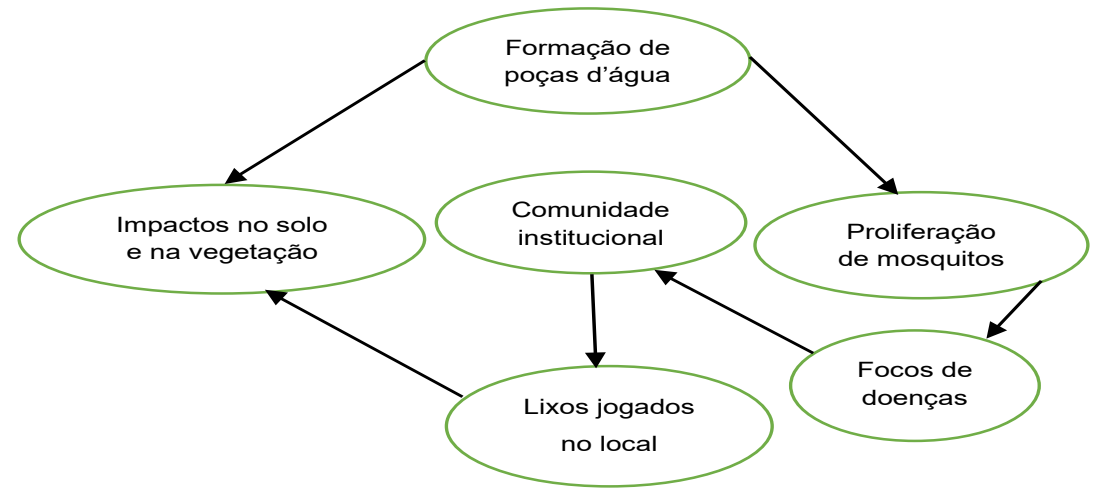

Fonte: Os autores.

Dialogamos com os participantes sobre as implicações da Figura 2, quando os lixos jogados no local também provocam impactos no solo e na vegetação. Ao tratarem sobre as medidas para a minimização dos impactos ambientais, descreveram minuciosamente as ações necessárias para a redução de danos no ambiente, como monitoramento das bombas de abastecimento da água, para que a água da caixa d'água não transborde; recuperação da fertilidade do solo; reflorestamento das vegetações possivelmente afetadas pelo acúmulo excessivo de água sobre o solo com plantas de fácil adaptação ao ambiente; monitoramento do acúmulo de água em lugares onde não há escoamento, provocando o acúmulo de mosquitos que causam doenças; intervenção com métodos de proteção do local, por exemplo a colocação de telas e placas informativas; sensibilização da comunidade institucional por meio de atividades que proporcionem o envolvimento e a participação no meio ambiente; e métodos de prevenção de incêndios.

Nas campanhas de Educação Ambiental, compreenderam a importância da sensibilização a fim de aproximar a comunidade institucional ao Horto com a Educação Ambiental vivencial e ações expositivas com placas decorativas para a sensibilização, o uso do próprio documentário e a criação de panfletos suscintos sobre os problemas no Horto.

Reuniu-se, dessa forma, os aspectos ambientais, socioculturais, técnico-organizacionais e as relações com a saúde e o meio-ambiente. As atividades desenvolvidas nessa oficina vão ao encontro das orientações presentes nas DCNs (BRASIL, 2013) para atividades integradoras, e corroboram os pressupostos de Ramos (2008), no entendimento de que a principal função da educação integrada é proporcionar ao discente a compreensão global da realidade e as inter-relações das partes que a formam. Destacamos, ainda, na produção do documentário, o protagonismo dos alunos na criação de conteúdos e, ainda, a contribuição para o desenvolvimento da leitura e escrita, conforme analisado por Oechsler, Fontes e Borba (2017).

Para a quarta oficina decidimos os elementos necessários para a elaboração do roteiro, com discussão coletiva. Esse momento exigiu muita paciência, pois todos queriam falar ao mesmo tempo e se encontravam inquietos com a iminência das gravações. Consideramos, aqui, a proposta de projeto de trabalho referenciada em Hernández e Ventura (2017), na qual os alunos, após a escolha do tema e de sua pesquisa em busca de novas informações, discutiram, em grupo, a partir do material construído nas oficinas, 
a estrutura do documentário. Seguimos para a estrutura discursiva narrativa do vídeo, com as etapas propostas por Soares (2007): pré-produção, produção e pós-produção. O roteiro dividiu-se em: início, com abordagem da história do Horto; desenvolvimento, com exploração dos principais argumentos - as doenças causadas pela proliferação de mosquitos, o desperdício de água, a infertilidade do solo, o lixo jogado no local, os riscos de incêndio e, por consequência, as possíveis incidências na saúde da comunidade institucional; resultados, com possíveis soluções - planejamento ambiental e atribuições do técnico em controle ambiental relacionadas à atuação em ambientes degradados; finalização, com opiniões anônimas sobre os lixos descartados incorretamente no local. Os depoimentos sustentaram a estrutura narrativa e o ambiente de produção foi o Horto, onde os discentes exploraram a temática socioambiental.

Para a quinta oficina trabalhamos algumas noções de enquadramento e gravação de vídeo, de modo que as imagens do celular não ficassem estremecidas. O videodocumentário foi feito com o auxílio dos celulares dos alunos para as gravações, o que demonstrou ser satisfatório para a produção de vídeos a baixo custo, conforme Moletta (2019).

A sexta oficina ocorreu no Horto, onde os participantes capturaram as imagens do Horto e gravaram vídeos do ambiente. A gravação dos depoimentos adveio no decorrer da semana. Salientamos que, para abordar o processo de produção, um projeto de trabalho foi devidamente organizado integrando práticas interdisciplinares. $\mathrm{O}$ uso das Tecnologias de Informação e Comunicação - as TIC -, de acordo com Kenski (2012), requer um planejamento pedagógico e operacionalização didática. Trata-se da exploração do recurso de produção de vídeo de forma integrada ao processo educacional, não sendo uma ferramenta aleatória.

Para a sétima oficina procedemos a avaliação das questões trabalhadas durante o curso. As respostas obtidas demonstraram que os alunos compreenderam as inter-relações dos elementos ambientais no Horto com as questões sociais. Após as atividades desenvolvidas nas oficinas, não veem os problemas do Horto como algo isolado, mas, sim, como parte de um Sistema que integra a comunidade institucional, quando é premente a sensibilização para que todos se percebam como parte constituinte do meio ambiente. Dessa forma, os alunos compreenderam, por meio de diferentes saberes, uma realidade que serviu como temática para o desenvolvimento do documentário (RAMOS, 2008). Do mesmo modo, a contextualização do conhecimento promoveu a integração de diferentes áreas, contribuindo para as orientações das DCNs (BRASIL, 2013).

Além disso, como resultados de ação efetiva, podemos elencar que os monitores do Horto confeccionaram placas artesanais, criaram um símbolo de identificação visual e construíram uma página em Rede Social para a divulgação das atividades que ocorrem no Horto. Essas ações foram possíveis por meio da socialização das questões trabalhadas nas oficinas por intermédio de uma das participantes do curso de Extensão, que, além de aluna, também é monitora do Horto. Essa aluna, ao dialogar com os outros monitores e com o coordenador do Horto sobre as discussões no Curso de Extensão, ofereceu algumas sugestões trabalhadas nas oficinas, as quais foram acolhidas positivamente. 


\section{CONSIDERAÇÕES FINAIS}

A pesquisa contribuiu para a contextualização do conhecimento acerca de uma questão socioambiental, tornando-se relevante para a formação de estudantes do curso Técnico em Controle Ambiental. Dessa forma, a inclusão das TICs na operacionalização do currículo integrado favoreceu o envolvimento dos alunos, de forma dinâmica e interativa, funcionando como aliada do processo pedagógico e como facilitadora de práticas educativas integradoras e interdisciplinares. Dentro da perspectiva de educação profissional integrada, a omnilateralidade do sujeito pressupõe uma formação que compreenda o trabalho como princípio educativo, abrangendo a formação humana integral.

Nesse sentido, a produção colaborativa de um documentário socioambiental proporcionou a exploração de conceitos subjacentes à formação humana em consonância com a educação profissional, por meio da ludicidade. Ao mesmo tempo, os valores éticos na relação com o meio ambiente foram explorados de forma integrada aos conceitos surgidos em decorrência do trabalho de pesquisa realizado. As conexões alcançadas demonstraram, portanto, a interconexão dos saberes de forma contextual.

Salientamos que os estudantes compreendiam previamente as problemáticas socioambientais, no entanto com uma visão fragmentada e pontual, sem relações de causalidade e interconexões. Observamos, durante as oficinas, as inter-relações estabelecidas com produção de sentido para os estudantes. Ainda, as discussões coletivas proporcionaram a troca de saberes, o desenvolvimento da oralidade e a interação social.

Concluímos que o processo de produção colaborativa possibilitou a discussão de questões socioambientais de forma contextualizada e lúdica. Ressaltamos que, com a divulgação de material virtual do processo de produção do documentário, contribuímos para a replicabilidade do Produto Educacional, o qual poderá ser adaptado às realidades de diferentes contextos educativos.

Por fim, salientamos a importância de um estudo, a posteriori, que demonstre a efetividade da utilização da mídia educacional produzida por docentes de diferentes áreas curriculares.

\section{REFERÊNCIAS}

BARDIN, Laurence. Análise de conteúdo. Lisboa, Portugal: Edições 70, 2002.

BEHRENS. Marilda Aparecida. Projetos de Aprendizagem colaborativa num paradigma emergente. In: MORAN, José M.; MASETTO, Marcos; BEHRENS, Marilda. Novas tecnologias e mediação pedagógica. 21. ed. Campinas, SP: Papirus, 2013.

BRASIL. Diretrizes Curriculares Nacionais da Educação Básica. Brasília: MEC; SEB; Dicei, 2013. Disponível em: http://portal.mec.gov.br/index.php?option=com_docman\&view=download\&alias=15548-d-c-n-educacao-basica-nova-pdf\&Itemid=30192

Acesso em: 23 out. 2019.

BRASIL. Ministério do Meio Ambiente. Secretaria de Articulação Institucional e Cidadania Ambiental. Programa Nacional de Educação Ambiental. Educomunicação socioambiental: comunicação popular e educação. Organização Francisco de Assis Morais da Costa. Brasília: MMA, 2008. Disponível em: http://mma. gov.br/estruturas/educamb/_arquivos/txbase_educom_20.pdf

Acesso em: 21 nov. 2018.

CHARLOT, Bernard. Trabalho e educação: abordagens antropológica e sócio histórica. Da relação com o saber às práticas educativas. 1. ed. São Paulo: Cortez, 2013. 
CIAVATTA, Maria. Trabalho como princípio educativo na sociedade contemporânea. Síntese do texto discutido com os participantes do Seminário Nacional de Formação - MST, realizado na Escola Nacional Florestan Fernandes em março de 2005. Disponível em: http://www.forumeja.org.br/files/Programa\%205.pdf. Acesso em: 21 nov. 2018.

CIAVATTA, Maria; RAMOS, Marise. Ensino Médio e Educação Profissional no Brasil - dualidade e fragmentação. Revista Retratos da Escola, Brasília, v. 5, n. 8, p. 27-41, jan./jun. 2011. Disponível em: http//www. esforce.org.br. Acesso em: 23 out. 2019.

DEMO, Pedro. Elementos metodológicos da Pesquisa participante: In: BRANDÃO, Carlos Rodrigues. Repensando a pesquisa participante. São Paulo, Brasiliense, 1984. p. 104-126.

FRIGOTTO, Gaudêncio. Educação e trabalho: bases para debater a educação profissional emancipadora. Perspectiva, Florianópolis, v. 19, n. 1, p. 71-87, jan./jun. 2001. Disponível em: https://periodicos.ufsc.br/ index.php/perspectiva/article/view/8463/7770. Acesso em: 24 nov. 2018.

GRÜN, Mauro. Ética e educação ambiental: a conexão necessária. 14. ed. Campinas, SP: Papirus, 2012.

HERNÁNDEZ, Fernando; VENTURA, Montserrat. A organização do currículo por projetos de trabalho: o conhecimento é um caleidoscópio. 5. ed. Porto Alegre: Penso, 2017.

KENSKI, Vani Moreira. Educação e tecnologias: o novo ritmo da informação. 8. ed. Campinas, SP: Papirus, 2012.

LE BOTERF, Guy. Pesquisa participante: propostas e reflexões metodológicas. In: BRANDÃO, Carlos Rodrigues. Repensando a pesquisa participante. São Paulo: Brasiliense, 1984. p. 51-81.

LUKÁCS, Georg. As bases ontológicas do pensamento e da atividade do homem. Texto publicado em 1969, em húngaro, sendo depois editado em alemão (1970) e em italiano (1972). Tradução Carlos Nelson Coutinho. Disponível em: http://www.giovannialves.org/Bases_Luk\%E1cs.pdf. Acesso em: 24 nov. 2018.

MINAYO, Maria Cecília de Souza (org.). Pesquisa social: teoria, método e criatividade. 29. ed. Petrópolis, RJ: Vozes, 2010.

MOLETTA, Alex. Criação de curta-metragem em vídeo digital: uma proposta para produções de baixo custo. 4. ed. São Paulo: Summus, 2019.

OECHSLER, Vanessa; FONTES, Bárbara Cunha; BORBA, Marcelo de Carvalho. Etapas da produção de vídeos por alunos da educação básica: uma experiência na aula de matemática. Revista Brasileira de Educação Básica, Belo Horizonte, on-line, v. 2, n. 2, 2017. ISSN 2526-1126. Disponível em: https://rbeducacaobasica.com.br/etapas-da-producao-de-videos-por-alunos-da-educacao-basica-uma-experiencia-na-aula-de-matematica/. Acesso em: 23 out. 2019.

RAMOS, Nogueira Marise. Concepção do Ensino Médio integrado. Seminário sobre ensino médio, realizado pela Superintendência de Ensino Médio da Secretaria de Educação do Estado do Rio Grande do Norte, em Natal e Mossoró; aspectos do debate realizado no seminário promovido pela Secretaria de Educação do Estado do Pará. Maio 2008. Disponível em: https://tecnicadmiwj.files.wordpress.com/2008/09/texto-concepcao-do-ensino-medio-integrado-marise-ramos1.pdf. Acesso em: 24 nov. 2018.

ROCHA, Marcelo Borges; MATTOS, Marcelo Nogueira. Análise das contribuições da produção de documentários ambientais na formação de estudantes do curso de tecnólogo em gestão ambiental. ENCONTRO NACIONAL DE ENSINO DE CIÊNCIAS DA SAÚDE E DO AMBIENTE, 4., Niterói, RJ, 2014. Disponível em: http://docs.wixstatic.com/ugd/a1a368_710059be38194a6ab4c98281436f720f.pdf. Acesso em: 21 nov. 2018.

SEVERINO, Antônio Joaquim. Metodologia do trabalho científico. 24. ed. São Paulo: Cortez, 2016.

SOARES. Sérgio J. Puccin. Documentário e roteiro de cinema: da pré-produção à pós-produção. 2007. Tese (Doutorado em Multimeios) - Universidade Estadual de Campinas, Programa de Pós-Graduação em Multimeios do Instituto de Artes. Orientador: Prof. Dr. Fernão Vitor Pessoa de Almeida Ramos, Campinas, 2007. 